\title{
Badania zdolności kapilarnych lutu BNi2 metodą zmiennej szczeliny lutowniczej
}

\author{
Study of capillary power of BNi2 braze \\ by variable clearance method
}

\section{Streszczenie}

Na podstawie badań zwilżalności i rozpływności oraz próby klinowej określano właściwości kapilarne lutu niklowego BNi2 dla podłoży ze stopu Inconel 625 oraz stali nierdzewnej martenzytycznej 410 po różnym przygotowaniu powierzchni: polerowaniu ścierniwem, kulowaniu NicroBlasting ${ }^{\circledR}$ i obróbce strumieniowo-ściernej. Lut miał postać litej folii i komercyjnej pasty lutowniczej. Stwierdzono, iż BNi2 ma korzystne właściwości kapilarne: dobrze zwilża i wypełnia szczeliny lutownicze o szerokości nawet powyżej $500 \mu \mathrm{m}$. Zastosowanie pasty lutowniczej w procesie próżniowym może powodować porowatość złączy i nadmierne wycieki lutu. Obróbka strumieniowo-ścierna nie jest zalecana przed lutowaniem, zwłaszcza dla stali 410.

Słowa kluczowe: lut BNi2; właściwości kapilarne; zmienna szczelina lutownicza

\begin{abstract}
Capillary properties of BNi2 nickel braze were studied basing on the wettability and spreadability experiments along with the slope sample test for Inconel 625 and 410 stainless steel substrates with the surfaces prepared by abrasive polishing, NicroBlasting ${ }^{\circledR}$ shot-peening and abrasive blasting. The filler metal was employed in the form of the solid foil and of commercial brazing paste. It was found $\mathrm{BNi} 2$ features high capillary properties: good wetting and filling the gaps even of above $500 \mu \mathrm{m}$ width. The application of brazing paste in a vacuum process can cause porosity of joints and excessive braze outflow. Abrasive blasting is not recommended prior to brazing, especially for 410 stainless steel.
\end{abstract}

Keywords: BNi2 braze; capillary properties; variable brazing clearance

\section{Wstęp}

Poprzez właściwości kapilarne lutu rozumie się jego zdolność do wypełniania w stanie ciekłym szczelin, których szerokość jest na tyle mała, aby wytworzone zostało ciśnienie kapilarne $\Delta \mathrm{P}$. Jest ono równe różnicy ciśnień po obu stronach zakrzywionej powierzchni cieczy. Generalnie uważa się, iż w danej temperaturze wpływanie ciekłego metalu do kapilary jest zależne z jednej strony od wielkości tego ciśnienia, stanowiącego siłę motoryczną procesu i będącego funkcją stopnia zwilżalności materiału ścianek i geometrii szczeliny oraz - z drugiej - sił oporu kinetycznego, związanego z lepkością i gęstością cieczy [1]. W praktyce technologicznej wielkość szczeliny lutowniczej dobiera się w zależności od składu stosowanego lutu, rodzaju materiału lutowanego (złącza jedno- i różnoimienne), konfiguracji złącza, techniki lutowania, stosowanego topnika lub atmosfery ochronnej, przygotowania powierzchni [2], uwzględniając zarazem specyfikę procesu, jak np. blokowanie przepływu cieczy o składzie eutektycznym przez wydzielenia faz pierwotnie krystalizujących z ciekłego lutu [3,4].

W niniejszej pracy badano stopień wypełnienia lutem niklowym BNi2 szczeliny lutowniczej o zmiennej szerokości dla dwóch różnych materiałów, stopu Inconel 625 oraz stali 410, w zależności od postaci stosowanego lutu (folia, pasta) oraz metody przygotowania powierzchni.

\section{Stosowane materiały}

Jako podłoża stosowano stop niklu Inconel 625 (AMS 5599) oraz stal martenzytyczną typu 410 (AMS 5504). Skład chemiczny obu materiałów podano $w$ tabicy I i II.

Tablica I. Skład chemiczny stopu Inconel 625 (AMS 5599) [5]

Table I. Chemical composition of Inconel 625 alloy (AMS 5999) [5]

\begin{tabular}{|c|c|c|c|c|c|c|c|c|c|c|c|c|c|}
\hline \multirow{2}{*}{ Materiał } & \multicolumn{13}{|c|}{ Zawartość procentowa pierwiastków [\% wag.] } \\
\hline & $\mathrm{Ni}_{\text {min }}$ & $\mathrm{Cr}$ & $\mathrm{Fe}_{\max }$ & Mo & $\mathrm{Nb}+\mathrm{Ta}$ & $\mathbf{C}_{\max }$ & $\mathrm{Mn}_{\max }$ & $\mathrm{Si}_{\max }$ & $\mathbf{P}_{\max }$ & $S_{\max }$ & $\mathbf{A l}_{\max }$ & $\mathrm{Ti}_{\max }$ & $\mathrm{Co}_{\max }$ \\
\hline Inconel 625 & 58 & $20 \div 23$ & 5 & $8 \div 10$ & $3,15 \div 4,15$ & 0,1 & 0,5 & 0,5 & 0,015 & 0,015 & 0,4 & 0,4 & 1,0 \\
\hline
\end{tabular}

Dr inż. Mariusz Bober; dr inż. Jerzy Jakubowski; prof. dr hab. inż. Jacek Senkara - Zakład Inżynierii Spajania, Politechnika Warszawska. Autor korespondencyjny/Corresponding author. mbober@wip.pw.edu.pl 
Tablica II. Skład chemiczny stali 410 (AMS 5504) [6]

Table II. Chemical composition of 410 steel (AMS 5504) [6]

\begin{tabular}{|c|c|c|c|c|c|c|c|}
\hline \multirow{2}{*}{ Materiał } & \multicolumn{7}{|c|}{ Zawartość procentowa pierwiastków [\% wag.] } \\
\hline & $C$ max & Si max & Mn max & $P$ max & $S \max$ & $\mathrm{Cr}$ & $\mathrm{Fe}$ \\
\hline Stal 410 & 0,15 & 1,0 & 1,0 & 0,040 & 0,030 & $11,5-13,5$ & reszta \\
\hline
\end{tabular}

Tablica III. Skład chemiczny lutu BNi2 (AMS 4777) [7]

Table III. Chemical composition of BNi2 braze (AMS 4777) [7]

\begin{tabular}{|c|c|c|c|c|c|c|c|c|}
\hline & \multicolumn{6}{|c|}{ Zawartość procentowa pierwiastków [\% wag.] } & \multicolumn{3}{c|}{ Temperatura [ ${ }^{\circ}$ C] } \\
\cline { 2 - 10 } & $\mathbf{C r}$ & $\mathrm{Fe}$ & $\mathrm{Si}$ & $\mathbf{C}$ & $\mathrm{B}$ & $\mathrm{Ni}$ & solidus & likwidus \\
\hline Inconel 625 & 7,0 & 3,0 & 4,5 & 0,06 & 3,1 & reszta & 971 & 999 \\
\hline
\end{tabular}

Materiał dodatkowy stanowił lut na bazie niklu o symbolu BNi2 (AMS 4777). Skład chemiczny oraz zakres temperatury solidus-likwidus przedstawiono w tablicy III. Lut stosowano w postaci pasty lutowniczej oraz folii o grubości $0,508 \mathrm{~mm}$ $(0,02 ")$ i szerokości $25,4 \mathrm{~mm}(1,0 ")$. W przypadku folii mamy do czynienia z "czystym" materiałem dodatkowym o danym składzie, natomiast pasta składa się jeszcze z nośnika, aktywatora i ewentualnie innych dodatków (producenci nie ujawniają składów past i proporcji składników).

\section{Oddziaływanie lutu z powierzchnią płaską}

Badania w tym zakresie polegały na wykonaniu prób zwilżania i rozpływności lutu na powierzchniach płaskich próbek z obu badanych materiałów. Testowano podłoża o wymiarach $20 \times 20 \times 1 \mathrm{~mm}$ po różnych, typowo stosowanych w przemyśle wariantach przygotowania powierzchni: polerowaniu ścierniwem No 120, obróbce strumieniowo-ściernej (piaskowaniu ziarnami $120 \mu \mathrm{m}$ ), kulowaniu śrutem niklowym (technologia NicroBlasting ${ }^{\circledR}$ ) i niklowaniu galwanicznym. Lut w postaci taśmy cięto na odcinki o równej długości i masie $0,11 \mathrm{~g}$, które zwijano w kształt pobocznicy walca dla zapewnienia jednakowej wyjściowej formy geometrycznej. Testy zwilżania i rozpływności prowadzono w w próżni $10^{-4} \mathrm{hPa}$ w specjalnym urządzeniu do badań zjawisk powierzchniowych [8].
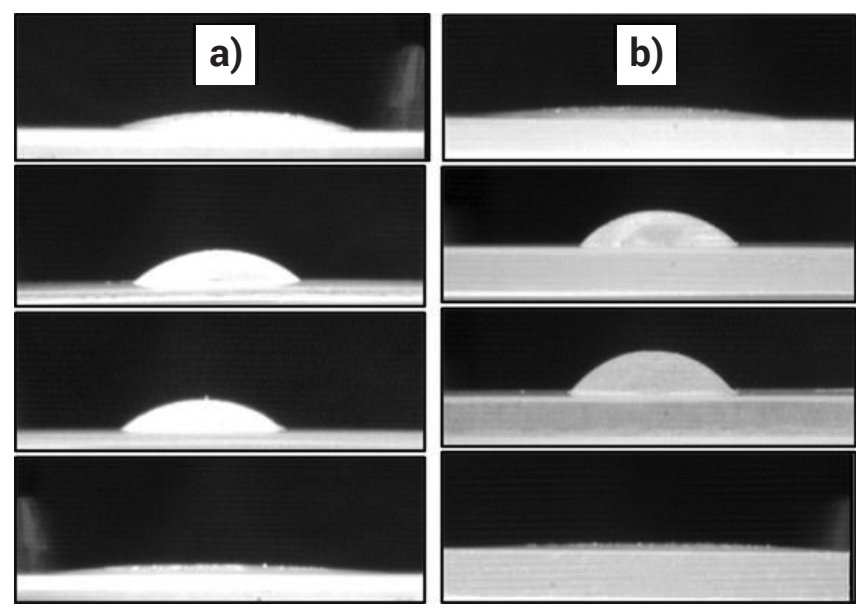

Rys. 1. Kształt kropli ciekłego lutu BNi2 na podłożu ze stopu Inconel 625 (a) i stali 410 (b) w temperaturze $1030^{\circ} \mathrm{C}$. W kolejności od góry powierzchnie po: polerowaniu ścierniwem, kulowaniu NicroBlasting ${ }^{\circledR}$, obróbce strumieniowo-ściernej, niklowaniu galwanicznym Fig. 1. Shapes of the liquid BNi2 braze droplets over the substrate of Inconel 625 alloy (a) and 410 stainless steel (b) at a temperature of $1030^{\circ} \mathrm{C}$. Surfaces from the top are: after abrasive polishing, after NicroBlasting ${ }^{\circledR}$ shot peening, abrasive blasting, and nickel plating

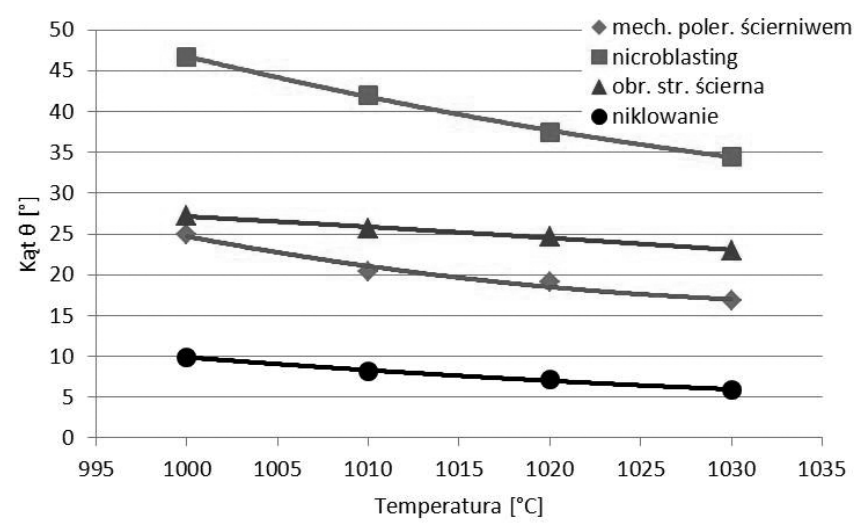

Rys. 2. Zależność kąta zwilżania od temperatury dla układu lut BNi2 - Inconel 625 po wariantowym przygotowaniu powierzchni

Fig. 2. Relationship between the contact angle and temperaturę for BNi2 braze - Inconel 625, after the different surface preparation

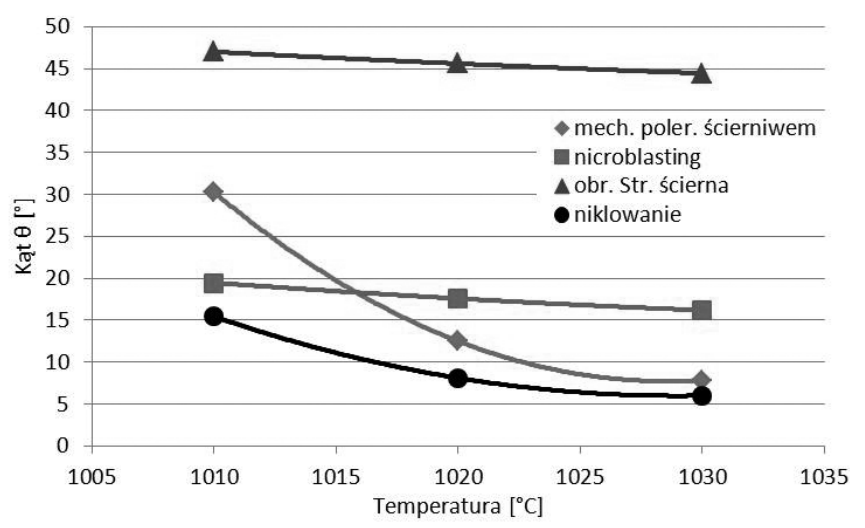

Rys. 3. Zależność kąta zwilżania od temperatury dla układu lut BNi2 - stal 410 po wariantowym przygotowaniu powierzchni

Fig. 3. Relationship between the contact angle and temperatue for BNi2 braze - 410 steel, after the different surface preparation

Próbki podłoży z nałożonym lutem nagrzewano z szybkością $200{ }^{\circ} \mathrm{C} / \mathrm{min}$ do temperatury $960^{\circ} \mathrm{C}$, a następnie $20^{\circ} \mathrm{C} / \mathrm{min}$ aż do osiągnięcia temperatury $1050^{\circ} \mathrm{C}$, zakładając iż mała szybkość nagrzewania po pojawieniu się stanu ciekłego umożliwia ciągłe osiąganie przez kroplę kształtu równowagowego w miarę wzrostu temperatury. Co 30 sekund rejestrowano kontur kropli za pomocą kamery CCD. Badania powtarzano trzykrotnie dla każdego układu podłoże-lut. Przykładowy kształt kropel ciekłego lutu pokazano na rysunku 1. Za pomocą programu komputerowego mierzono kąty zwilżania z obu stron kropli i uśredniano. Wyniki testów zwilżania dla stopu Inconel 625 oraz stali 410 przedstawiono odpowiednio na rysunku 2 i 3. 
Najlepszą zwilżalność wykazują, zgodnie z oczekiwaniem, podłoża niklowane, a następnie po polerowaniu mechanicznym. Większe kąty zwilżania występują dla powierzchni po obróbce NicroBlasting ${ }^{\circledR}$ oraz strumieniowo-ściernej.

Rozpływność określana była po krystalizacji lutu i wyjęciu próbek z pieca, na stanowisku wyposażonym w mikroskop stereoskopowy z cyfrowym zapisem obrazu. Pole powierzchni rozpływu mierzono przy pomocy odpowiedniego programu komputerowego. Wyniki w postaci średniej arytmetycznej z pomiaru trzech próbek przedstawiono na rysunkach 4 i 5.

\section{a)}

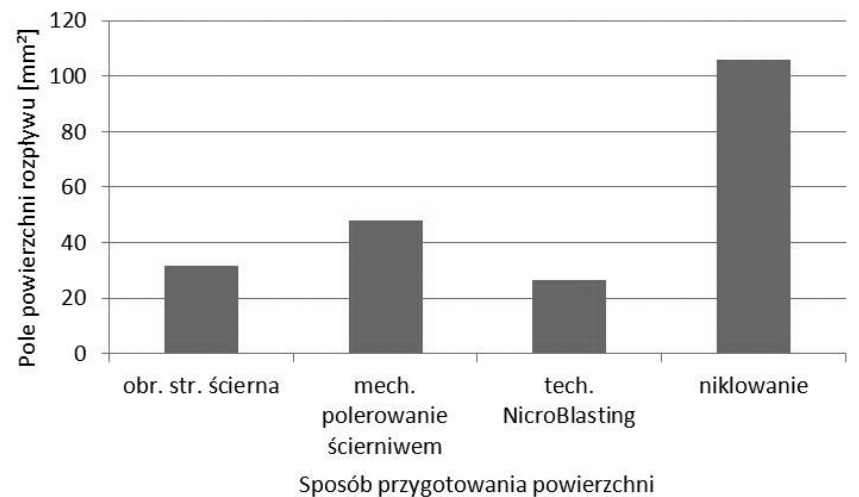

b)

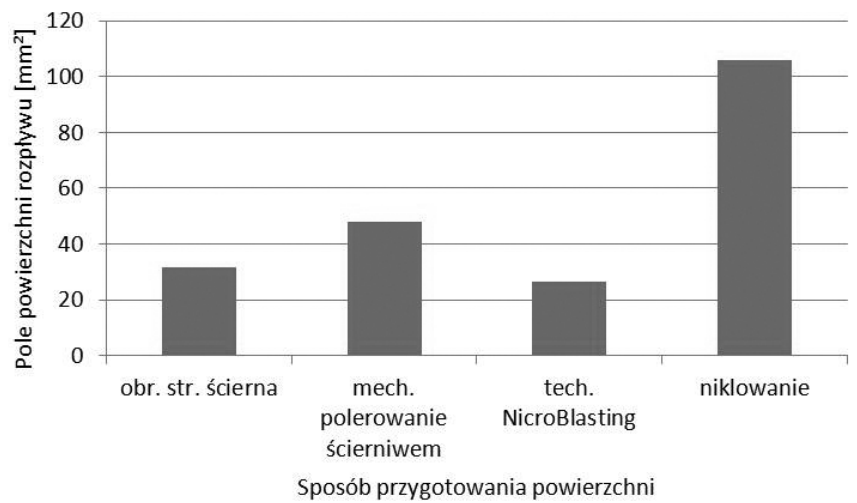

Rys. 4. Pole powierzchni rozpływu lutu BNi2 na podłożu ze stopu Inconel 625 (a) oraz na stali 410 (b) po wariantowym przygotowaniu powierzchni

Fig. 4. The surface area of BNi2 braze spread over Inconel 625 substrate (a) and over 410 steel (b) after the different surface preparation

Wyniki badań rozpływności odpowiadają poszczególnym przejawom zwilżalności. Najmniejsze pola rozpływu lutu występują na powierzchniach po obróbce strumieniowo-ściernej i obróbce NicroBlasting ${ }^{\circledR}$, największe - po niklowaniu galwanicznym.

\section{Wpływanie lutu do szczelin kapilarnych}

Badania prowadzono dla szczelin o zmiennej szerokości (tzw. próba klinowa) według znanej metodyki, stosowanej uprzednio $\mathrm{np}$. do badań lutowności materiałów trudnotopliwych [9], a także dla lutów niklowych [10], po niewielkiej jej modyfikacji. Pomiędzy końcami dwu jednakowych płytek sytuowano specjalny element dystansowy, którego wysokość i odległość od przeciwległego końca styku płytek była dobierana w taki sposób, aby uzyskać szczelinę o kącie rozwarcia $6^{\circ}$. W celu zachowania geometrii i stabilności całego układu końce płytek łączono w miejscu ich styku dwiema mikrozgrzeinami punktowymi.
Podobnie jak poprzednio, stosowano płytki ze stopu Inconel 625 i stali 410 po polerowaniu ścierniwem o ziarnistości 120, obróbce strumieniowo-ściernej i obróbce NicroBlasting $^{\circledR}$, o wymiarach $76,2 \times 25,4 \times 0,61$ mm (3"x1"x0,024"). Lut w postaci taśmy o stałej masie układano na płytce dolnej, a pasta lutownicza aplikowana była za pomocą dozownika w obszar przed klinem. Próbki nagrzewano w przemysłowym piecu próżniowym do temperatury $1065^{\circ} \mathrm{C}$ w próżni $3 \times 10^{-3} \mathrm{hPa}$, wytrzymywano $15 \mathrm{~min}$ i chłodzono, początkowo z piecem, a później forsownie w atmosferze argonu do temperatury pokojowej.

Próbki cięto w płaszczyźnie prostopadłej do powierzchni płytek w części środkowej klina i wykonywano zgłady metalograficzne. Z pomocą programu komputerowego wyznaczano charakterystyczne parametry: głębokość penetracji Ix oraz szerokość szczeliny Sx w miejscu menisku (rys. 5). Uśrednione wyniki pomiarów pokazano na rysunkach $6 \div 10$.

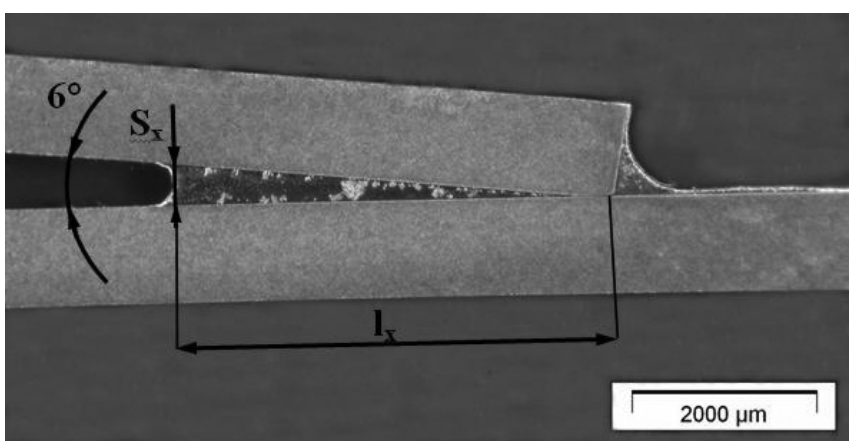

Rys. 5. Zgład próbki Inconel 625 - lut BNi2 po próbie klinowej z zaznaczonymi wielkościami lx i Sx (stan wyjściowy lutu - pasta) Fig. 5. Metallographic cross-section of Inconel 625 - BNi2 braze specimen after the slope sample test, Ix and Sx sizes are marked. The initial state of the braze was paste

a)

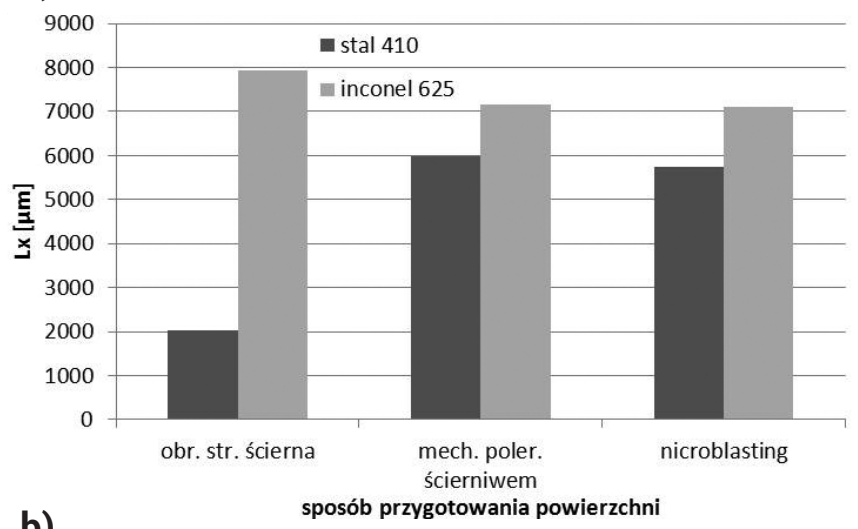

b) sposób przygotowania powierzchni

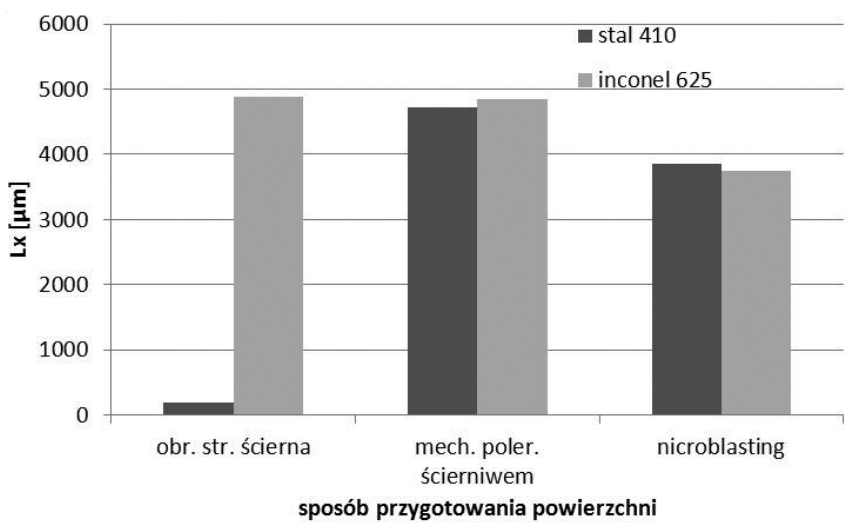

Rys. 6. Zasięg penetracji lutu BNi2 w próbie klinowej; stan wyjściowy lutu: folia (a), pasta (b)

Fig. 6. The range of $\mathrm{BNi} 2$ braze penetration after the slope sample test: (a) the initial state of the braze was foil; (b) paste 
a)

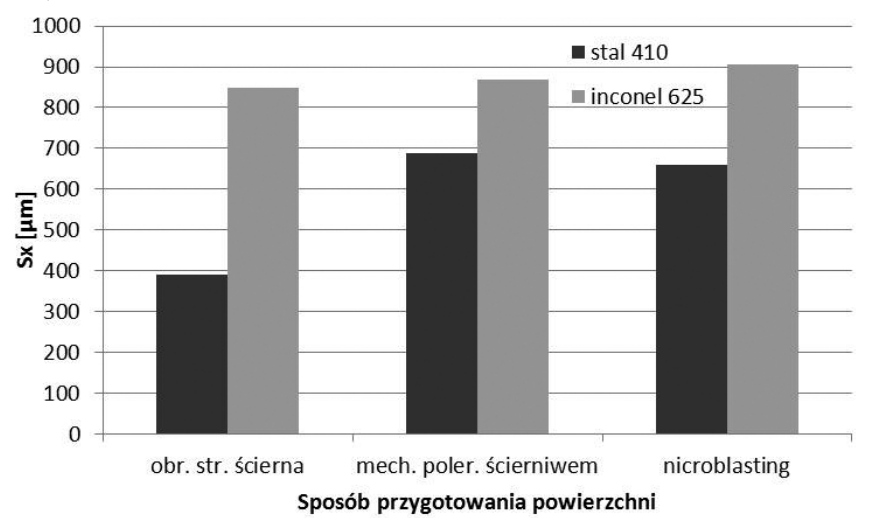

b)

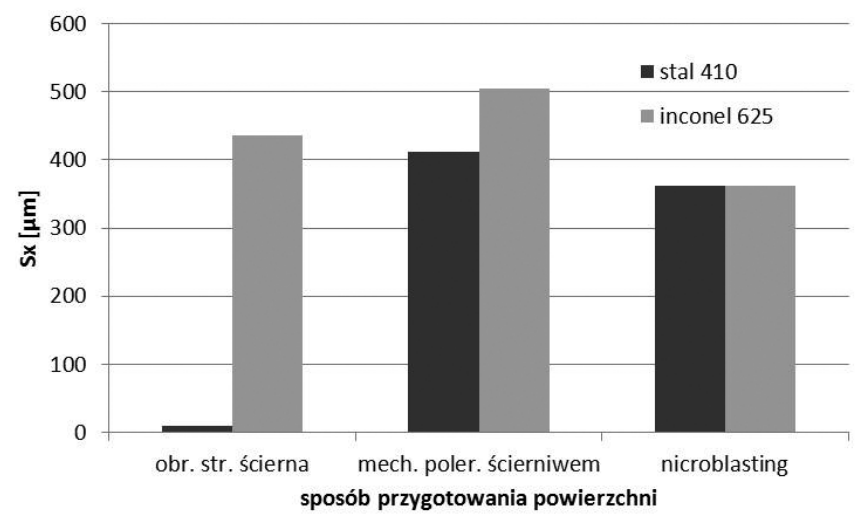

Rys. 7. Maksymalna szerokość szczeliny wypełnionej lutem BNi2; stan wyjściowy lutu: folia (a), pasta (b)

Fig. 7. The maximum gap width (Sx) filled with BNi2 braze: (a) the initial state of the braze - foil; (b) paste

Badania struktury próbek wskazują na dobre wypełnienie szczelin we wszystkich wariantach, dla obu spajanych materiałów, przy czym dla lutu w formie pasty lutowniczej występuje $z$ reguły $w$ spoinie lokalna porowatość. Jest to niewątpliwie efekt pozostałości gazowych produktów rozkładu nośnika pasty, trudnych do usunięcia z kapilar, nawet przy prowadzeniu procesu w próżni. Można było zaobserwować również wyraźne efekty oddziaływania lut - podłoże w po- staci strefy przejściowej na granicy międzyfazowej. Na rysunku 8 przedstawiono dla ilustracji typową mikrostrukturę lutowin dla stopu Inconel 625.

Wyniki badań wskazują na łatwe spełnienie wymagań dotyczących wielkości szczeliny dla lutów na osnowie Ni (do $130 \mu \mathrm{m}$ [1]), ale przy doborze jej optymalnej szerokości należy brać pod uwagę wytrzymałość złącza (rekomendacja AWS do $20 \mu \mathrm{m}$ [2]). Generalnie wartości wskaźników Ix i Sx wypełnienia szczeliny są nieco lepsze dla Inconelu 625 niż stali 410 we wszystkich wariantach (z wyjątkiem obróbki strumieniowościernej, podczas której powstają na powierzchni stali trudne do usunięcia tlenki) i wyraźnie większe dla lutu w postaci litej niż w formie pasty (rys. 6-7). Jest to jednak mylące, gdyż w przypadku pasty lutowniczej obecność aktywatora w nośniku zapewnia tak doskonałą zwilżalność, iż lut penetruje poprzez styk obu płytek formując menisk po drugiej stronie i rozpływa się po płaskiej powierzchni (rys. 5 oraz 8a), powodując deficyt objętości cieczy dla dalszego wypełniania szczeliny o zwiększonej szerokości. Jest to z jednej strony korzystne (dobre wypełnianie małych szczelin), z drugiej - kłopotliwe w praktyce przemysłowej (nadmierne wycieki lutu ze złącza).
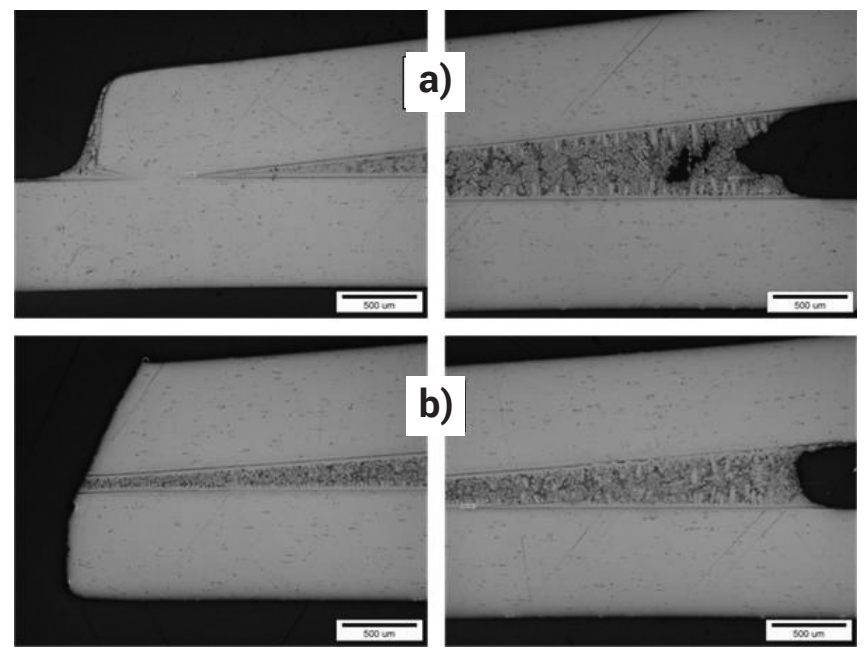

Rys. 8. Mikrostruktura połączenia stopu Inconel 625 lutem BNi2 w postaci pasty (a) oraz litej folii (b)

Fig. 8. The microstructure of Inconel 625 joint performed by BNi2 braze in the initial form of the paste (a) and the solid foil (b)

\section{Wnioski}

- Analizując przytoczone wyniki można ogólnie stwierdzić, iż lut BNi2 ma bardzo dobre właściwości kapilarne, o czym świadczy zdolność wypełniania szczelin lutowniczych o dużej szerokości, nawet powyżej $500 \mu \mathrm{m}$, dla stopu Inconel 625 i stali 410.

- Zastosowanie lutu BNi2 w postaci pasty dla przypadku lutowania próżniowego powinno być kontrolowane z uwagi na możliwość powstawania porowatości w złączach oraz nadmierne wyciekanie lutu wymuszające konieczność stosowania środków zapobiegających (np. pasta stop-off).

- Przygotowanie powierzchni poprzez zastosowanie obróbki strumieniowo-ściernej nie jest zalecane, zwłaszcza w przypadku stali stopowej 410.

Badania były finansowane z grantu NCBiR nr PBS 177902, nr umowy PBS1/B5/11/2012.

\section{Literatura}

[1] Eustathopoulos N., Nicholas M.G., Drevet B.: „Wettability at High Temperatures”, Pergamon Material Series, Pergamon 1999

[2] AWS Brazing Handbook, 5th Edition, AWS 2007

[3] Babul T., Kowalski S., Senkara J., Jakubowski J., Gancarczyk T.: „Zastosowanie lutów na bazie srebra i złota do lutowania wybranych części silników lotniczych", Inżynieria Powierzchni, 44-52, 2007

[4] Dul I., Kopeć J., Poradka A., Turowska L., Babul T., Kowalski S, Jakubowski J, Senkara J.: „Wpływ wybranych czynników technologicznych na proces lutowania próżniowego stopów Ni i stali wysokostopowej 18-8", Przegląd Spawalnictwa 81 (10), 77-80, 2009

[5] „Nickel Alloy, Corrosion and Heat-Resistant, Sheet, Strip, and Plate, $62 \mathrm{Ni}-21.5 \mathrm{Cr}$ 9.0Mo - 3.7 Cb (Nb), Solution Heat Treated". AMS Standard No 5599.

[6] High Temp. Metals. Technical Data. http://www.hightempmetals.com
[7] „Steel, Corrosion and Heat-Resistant, Sheet, Strip, and Plate, 12.5Cr (SAE 51410), Annealed". AMS Standard No 5504. http://www.aircraftmaterials.com

[8] „Nickel Alloy, Brazing Filler Metal 82Ni 4.5Si 7.0Cr 3.1B 3.0Fe, 1780 to $1830^{\circ} \mathrm{F}(971$ to $999^{\circ} \mathrm{C}$ ) Solidus-Liquidus Range". AMS Standard No 4777. http://princeizant.com/ product/ams-4777

[9] Bober M.: „Oddziaływania międzyfazowe w technologii napawania plazmowego warstw na osnowie Ni z węglikami metali przejściowych". Rozprawa doktorska WIP PW, Warszawa, 2009

[10] Mirski Z. "Sterowanie szerokością szczeliny lutowniczej w procesach spajania materiałów różnoimiennych", Oficyna Wydawnicza Politechniki Wrocławskiej, Wrocław 2000

[11] Miyazawa Y., Saito K., Fukikoshi T., Ariga T.: „Brazing of ferritic stainless steel and microstructure of the brazed joints". Proc. of 5th IBSC Conference, Las Vegas 2012, pp. 236-239 